\title{
Value Co-Creation Among Enterprises in Green Supply Chain Based on Free Riding Behavior
}

\author{
Xiuli Liu ${ }^{1, *}$ \\ ${ }^{1}$ School of Economics and Management, Beijing Jiaotong University, P.R.China, 100044 \\ ${ }^{*}$ Corresponding author. Email: 19120582@bjtu.edu.cn
}

\begin{abstract}
In this paper, we consider the situation of free riding behavior of retailers in the green secondary supply chain of manufacturing industry. Based on game theory and value co-creation theory, we discuss the impact of centralized decision-making and decentralized decision-making on product green degree, price and profit. We further build two value co-creation models of cost sharing and value distribution, and compare the four models and conduct numerical simulation. The results show that the overall profit is the highest under the overall decision-making, and the value co creation mode of cost sharing has no positive significance because there is no appropriate share proportion. By adjusting the value distribution proportion, the profit conflict between manufacturers and retailers can be coordinated to promote value co creation, which can provide certain guidance for manufacturing enterprises.
\end{abstract}

Keywords: Green supply chain, Value co-creation, Game model, Free riding behavior.

\section{INTRODUCTION}

With the continuous deterioration of the natural environment, more and more people have paid attention to the green supply chain (GSC) management. Especially in the manufacturing industry, on the one hand, the government has issued relevant policies, laws and regulations, the implementation of more stringent regulatory measures, and the emergence of green barriers to international trade, so that enterprises have to incorporate the GSC into the strategy of enterprises[1]. On the other hand, consumers' increasing awareness of environmental protection and green consumption concept have a certain preference in product selection, and enterprises will pay more attention to investment and innovation of green products in order to meet the needs of consumers. In practice, the government's regulatory policies are often aimed at manufacturers. In most cases, the manufacturers bear the investment cost of green products. However, the sales volume of green products may increase due to the environmental protection of their products, which may lead to the phenomenon of free riding and the conflict of interests between retailers and manufacturers. Therefore, in order to optimize the whole supply chain and coordinate the conflicts among the members of the supply chain, it is particularly important for enterprises to create value together.
Many scholars have made some achievements in green supply chain management. According to Dangelico and Pontrandolfo, the environmental protection of green products is usually expressed by the green degree of products, which is one of the important factors affecting consumers' purchase[2]. Members of the supply chain are actively seeking cooperation with the upstream and downstream to improve the green degree of products. It is impossible to achieve positive and effective GSC management by enterprises themselves [3]. $\mathrm{Ji}$ et al. studied the impact of cooperation between retailers and manufacturers on the economic performance and social welfare of enterprises in the GSC, and considered both online and offline situations [4]. Dai et al. analyzed two cooperation modes of green investment cost in two-level GSC, namely cartelization and cost sharing [5]. Zhang and Liu constructed a three-level GSC game model composed of manufacturers, suppliers and retailers, and compared four decision-making models: centralized decisionmaking, decentralized decision-making, cooperative game between manufacturers and consumers, and game between retailers and consumers [6].

At the same time, in the aspect of value co-creation, scholars have many research results, mainly focusing on the role of customers in value creation. According to the traditional view, value is created by enterprises, while 
consumers are the terminator and destroyer of value. Relevant scholars have found that cooperation between enterprises and customers will also have a positive impact on enterprises [7,8]. For example, Mai et al. studied that value co-creation between patients and hospitals in the medical industry can improve medical quality based on DART model [9]. There are few literatures on value co-creation among enterprises, and they mainly focus on the value co-creation of manufacturers and suppliers. The core of value cocreation among enterprises is interdependence and mutual trust, forming a more complex customized relationship, then cooperation may bring higher value than independent companies $[10,11]$.

In summary, although there are a lot of research results on GSC management and value co-creation, which also provide important reference for this paper, there are few studies in some aspects: (1) In the relevant literature of GSC management, considering the situation of free riding of retailers is less; Most the goal of the articles is close profit maximization, but the development of new technology has brought the possibility for supply chain members to realize the overall decision-making; In addition, value co-creation as an important mode in green supply chain management is less considered. (2) In the literature about value co-creation, there are few researches on value co-creation in manufacturing field and among enterprises. In view of this, from the perspective of value co creation, this paper constructs the centralized and decentralized decision-making models respectively, and considers the factors such as the free riding of retailers and the green degree of products, so as to obtain the influence of different decision-making modes. On this basis, two decision models of value cocreation are established and compared with the previous two models. This study not only enriches the application of value co-creation theory in green supply chain management, but also provides guidance management enlightenment for the cooperation between manufacturing enterprises.

\section{PROBLEM STATEMENT AND FORMULATION}

\subsection{Model Symbol Description}

Based on a two-level green supply chain (one manufacturer and one retailer), this paper studies the effects of centralized decision-making, decentralized decision-making and two value co creation models on the profit of each member and supply chain. The related symbols are shown in Table 1.

\subsection{Research Assumptions}

In this green supply chain, the market demand function is affected by retail price and green degree: $q=a-b p+m g$, where $b$ is the price sensitivity coefficient and $m$ is the environmental awareness of consumers, where $a>b q, b>0, q>0$.

Referring to the paper of Basiri and Heydari [12], the research and development cost function of the manufacturer is $c(g)=(1 / 2) \lambda g^{2}$. And the cost of green investment increases with the increase of green degree.

Suppose that the retailer and the manufacturer are risk neutral rational people, there is Stackelberg game between them.

\section{MODEL ANALYSIS OF NO VALUE CO- CREATION}

\subsection{Centralized Decision Model}

Under centralized decision-making, the manufacturer and retailer make decisions as a whole. The two entities no longer only care about their own interests, but also jointly determine the green degree and price of products with the goal of maximizing the profits of the whole supply chain. The overall decision function is as follows:

$\Pi_{S C}=(p-c)(a-b p+m g)-\frac{1}{2} \lambda g^{2}$

Proposition 1: under centralized decision-making, supply chain profit function is strictly concave function: $2 b \lambda-m^{2}>0$.

It is proved in the following.

The Hessian matrix of formula (1) is: $H_{1}(p, g)=\left[\begin{array}{ll}\frac{\partial^{2} \Pi_{s C}}{\partial^{2} p^{2}} & \frac{\partial^{2} \Pi_{s C}}{\partial p \partial g} \\ \frac{\partial^{2} \Pi_{s C}}{\partial p \partial g} & \frac{\partial^{2} \Pi_{s C}}{\partial^{2} g^{2}}\end{array}\right]=\left[\begin{array}{cc}-2 b & m \\ m & -\lambda\end{array}\right]$.

We can find that the first-order and second-order principals of the Hessian matrix are $D_{1}=-2 b<0, D_{2}=2 b \lambda-m^{2}$. Therefore, there are global optimal solutions $\mathrm{p} 1$ and $\mathrm{g} 1$ for this function.

We can first solve the first-order partial derivative function of the overall decision-making function with respect to sum $\mathrm{g}$ and make it equal to 0 , then we can obtain the optimal product green degree and retail price, and bring it into the market demand function to calculate the maximum demand:

$p_{1}=\frac{\lambda(a+b c)-c m^{2}}{2 b \lambda-m^{2}}, g_{1}=\frac{m(a-b c)}{2 b \lambda-m^{2}}, \quad q_{1}=\frac{b \lambda(a-b c)}{2 b \lambda-m^{2}}$ 
By substituting equation (2) into equation (1), the optimal supply chain profit under the overall decision can be obtained:

$\Pi_{s c}=\frac{\lambda(a-b c)^{2}}{2\left(2 b \lambda-m^{2}\right)}$

Table 1. Symbols and Descriptions of Research Models

\begin{tabular}{|c|c|c|c|}
\hline Symbols & Descriptions & Symbols & Descriptions \\
\hline$a$ & $\begin{array}{l}\text { Market base } \\
\text { demand for } \\
\text { product }\end{array}$ & $g$ & $\begin{array}{l}\text { Green degree } \\
\text { of products }\end{array}$ \\
\hline$c$ & $\begin{array}{c}\text { Unit production } \\
\text { cost }\end{array}$ & $\lambda$ & $\begin{array}{c}\text { Green } \\
\text { investment } \\
\text { coefficient }\end{array}$ \\
\hline$w$ & $\begin{array}{l}\text { Wholesale } \\
\text { price per unit } \\
\text { product }\end{array}$ & $q$ & $\begin{array}{l}\text { Market demand } \\
\text { for product }\end{array}$ \\
\hline$p$ & $\begin{array}{c}\text { Retail price per } \\
\text { unit product }\end{array}$ & $\theta$ & $\begin{array}{c}\text { Cost sharing } \\
\text { ratio }\end{array}$ \\
\hline$\alpha$ & \begin{tabular}{c|} 
Value \\
distribution \\
ratio
\end{tabular} & $\Pi$ & Profit function \\
\hline
\end{tabular}

\subsection{Decentralized Decision Model}

In practice, manufacturers and retailers make decisions with the goal of maximizing their own interests as rational people. In this paper, we consider that in a two-level green supply chain composed of manufacturers and suppliers, the investment cost of green products is paid by the manufacturer, while the retailer does not pay the green investment cost, but will enjoy the benefits of product greenness. First, the manufacturer determines the wholesale price and green degree according to the decision-making goal of maximizing their own interests, and the retailer determines the retail price with the goal of maximizing their own profits. The decision functions of manufacturers and retailers are as follows:

$$
\begin{aligned}
& \Pi_{M 1}=(w-c)(a-b p+m g)-\frac{1}{2} \lambda g^{2} \\
& \Pi_{R 1}=(p-w)(a-b p+m g)
\end{aligned}
$$

We use the inverse induction method to solve the problem. First, solve the first-order partial derivative of $\mathrm{p}$ for the retailer's profit function and zero it equals 0 , then $p_{2}=(a+b w+m g) / 2 b$. Then bring it into equation (4).

Proposition 2: The profit function of the retailer is a strictly concave function of, and the condition of the profit function of the manufacturer of the strictly convex function of $(p, g)$ is: $m^{2}-2 b \lambda<0$.

It is proved in the following.

The second derivative of equation (5) $\partial^{2} \Pi_{R 1} / \partial^{2} p=-2 b<0$, so the retailer's profit function is a strictly concave function about $p$.The Hessian matrix of equation (5) is: $H_{M 1}(w, g)=\left[\begin{array}{cc}-b & m \\ m & -\lambda\end{array}\right]$.

We can find that the first-order and second-order principals of the Hessian matrix are $D_{1}=-b<0$ and $D_{2}=2 b \lambda-m^{2}>0$. Therefore, the function has global optimal solutions $w_{1}$ and $g_{2}$.

Then make the first-order partial derivative of the manufacturer's profit function with respect to 0 , and combine the above formula to get the optimal decision:

$$
\begin{aligned}
& g_{2}=\frac{(a-b c) m}{4 b \lambda-m^{2}}, w_{1}=\frac{\lambda(a+2 b c)-c m^{2}}{4 b \lambda-m^{2}}, \\
& p_{2}=\frac{\lambda(2 a+b c)-c m^{2}}{4 b \lambda-m^{2}}, q_{2}=\frac{b \lambda(a-b c)}{4 b \lambda-m^{2}} \\
& \Pi_{M 1}=\frac{\lambda(a-b c)^{2}}{2\left(4 b \lambda-m^{2}\right)}, \Pi_{R 1}=\frac{\lambda^{2} b(a-b c)^{2}}{\left(4 b \lambda-m^{2}\right)^{2}}, \\
& \Pi_{S C 2}=\frac{\lambda\left(6 b \lambda-m^{2}\right)(a-b c)^{2}}{2\left(4 b \lambda-m^{2}\right)^{2}}
\end{aligned}
$$

Lemma 1: Calculated by equations (2), (3), (6), (7): $q_{1}>q_{2}, g_{1}>g_{2}, \Pi_{S C l}>\Pi_{S C 2}$.

Lemma 1 shows that when a manufacturer and a retailer play a Stackelberg game, whether it is the demand for the product, the greenness of the product, or the profit of the overall supply chain are smaller than the overall decision. Nowadays, it is no longer the competition between enterprises but the competition between supply chains. If enterprises want to be competitive, they need to cooperate with supply chain members. However, if the overall decision is taken, the demand for products will increase with the increase in greenness, but the manufacturer needs to pay for the investment in green technology alone, and the retailer will catch a ride. There will inevitably be a conflict of interest between the two and cannot reach a consensus. The overall decision-making, therefore, requires enterprises to create value for common goals. This article will discuss the value co-creation in two ways: cost sharing and value distribution.

\section{MODEL ANALYSIS OF VALUE CO- CREATION}

\subsection{Cost Sharing Model}

When value co-creation is not adopted among enterprises, all the investment cost is borne by the manufacturer. However, it can be seen from the above analysis that under decentralized decision-making, both the sales volume and the green degree and the overall profit of the supply chain will be reduced. Therefore, this section will discuss the impact of the value cocreation mode of cost sharing, and the condition for 
judging whether the co-creation mode has a positive effect is that compared with decentralized, manufacturing has a positive effect. The profits of both merchants and retailers increased. In this model, the decision-making order is that the manufacturer decides the wholesale price and green degree, and then the retailer decides the retail price and share proportion. The decision functions of manufacturers and retailers are as follows:

$$
\begin{aligned}
& \Pi_{M 2}=(w-c)(a-b p+m g)-\frac{1}{2}(1-\theta) \lambda g^{2} \\
& \Pi_{R 2}=(p-w)(a-b p+m g)-\frac{1}{2} \theta \lambda g^{2}
\end{aligned}
$$

First, take $\theta$ as a constant, and then get proposition 3 in the same way as the previous section.

Proposition 3: the retailer's profit function is strictly concave with respect to $p$. If the strictly convex function of the manufacturer's profit function with respect to $(p$, $g)$ is: $\theta<\left(2 b \lambda-m^{2}\right) / 2 b \lambda$.

It is proved in the following.

The second derivative of equation (9): $\partial^{2} \Pi_{R 2} / \partial^{2} p=-2 b<0$, so the retailer's profit function is a strictly concave function about $\mathrm{p}$. The Hessian matrix of

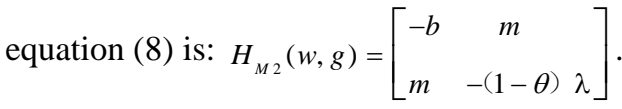

We can find that the first-order and second-order principals of the Hessian matrix are $D_{1}=-b<0$ and $D_{2}=2 b \lambda(1-\theta)-m^{2}$. Therefore, the function has global optimal solutions $w_{2}$ and $g_{3}$.

Then make the first-order partial derivative of the manufacturer's profit function with respect to 0 , and combine the above formula to get the optimal decision:

$$
\begin{aligned}
& g_{3}=\frac{(a-b c)(1-\theta) m}{2\left[2 b \lambda(1-\theta)^{2}+(2 t-1) m^{2}\right]}, \\
& w_{2}=\frac{\lambda(a+2 b c)(1-\theta)^{2}-c m^{2}}{2\left[2 b \lambda(1-\theta)^{2}+(2 t-1) m^{2}\right]}, \\
& p_{3}=\frac{\lambda(2 a+b c)(1-\theta)-c m^{2}}{2\left[2 b \lambda(1-\theta)^{2}+(2 t-1) m^{2}\right]}, \\
& q_{3}=\frac{b \lambda(a-b c)(1-\theta)^{2}}{2\left[2 b \lambda(1-\theta)^{2}+(2 t-1) m^{2}\right]} \\
& \Pi_{M 2}=\frac{\lambda(1-\theta)^{2}(a-b c)^{2}}{2\left[2 b \lambda(1-\theta)^{2}+(2 t-1) m^{2}\right]}, \\
& \Pi_{R 2}=\frac{\lambda^{2} b(a-b c)^{2}(1-\theta)^{2}}{2\left[2 b \lambda(1-\theta)^{2}+(2 t-1) m^{2}\right]^{2}}, \\
& \Pi_{S C 3}=\frac{\lambda\left(6 b \lambda-m^{2}-6 b \lambda \theta\right)(a-b c)^{2}}{2\left[2 b \lambda(1-\theta)^{2}+(2 t-1) m^{2}\right]}
\end{aligned}
$$

Lemma 2: According to formula (6), (7), (10) and (11), we know that the value of $\theta$ satisfied at $\Pi_{M 2}>\Pi_{M 1}, \Pi_{R 2}>\Pi_{R 1}$ the same time does not exist. That is, the value co-creation of cost sharing is meaningless, and the profit conflict between manufacturers and retailers can't be solved, which is not conducive to the development of green products and the cooperation between supply chains.

\subsection{Value Distribution Model}

Through the analysis of the previous section, we can see that the supply chain management can not achieve a coordinated state when the cost sharing method is adopted for value co creation. However, if we don't adopt the method of value co creation, we can't improve the profits of members and the whole supply chain, and it's not conducive to the development of green products. Therefore, this section puts forward the value co creation between the manufacturer and the supplier in order to improve the profit. The way is to maximize the overall profit and distribute the profit between the two. In this paper, the condition of value co creation is the same as that of cost sharing. Suppose the profit proportion of manufacturer is $\alpha$, the decision function is as follows:

$$
\begin{aligned}
& \Pi_{M 3}=\alpha\left[(p-c)(a-b p+m g)-\frac{1}{2} \lambda g^{2}\right] \\
& \Pi_{R 3}=(1-\alpha)\left[(p-c)(a-b p+m g)-\frac{1}{2} \lambda g^{2}\right]
\end{aligned}
$$

The optimal decision of each variable is the same as that of the centralized decision model. In order to make the value distribution meaningful, the following conditions should be met:

$$
\begin{aligned}
& \Pi_{M 3}=a\left[\frac{\lambda(a-b c)^{2}}{2\left(2 b \lambda-m^{2}\right)}\right]>\Pi_{M 1}=\frac{\lambda(a-b c)^{2}}{2\left(4 b \lambda-m^{2}\right)}, \\
& \Pi_{R 3}=(1-a)\left[\frac{\lambda(a-b c)^{2}}{2\left(2 b \lambda-m^{2}\right)}\right]>\Pi_{R 1}=\frac{\lambda^{2} b(a-b c)^{2}}{\left(4 b \lambda-m^{2}\right)^{2}}
\end{aligned}
$$

Proposition 4: No matter what value $b, \lambda, m$ take, the value co-creation of value distribution mode has positive significance.

It is proved in the following.

From equation (17), the value of $\alpha$ can be calculated as $\frac{2 b \lambda-m^{2}}{4 b \lambda-m^{2}}<\alpha<1-2 b \lambda \frac{2 b \lambda-m^{2}}{\left(4 b \lambda-m^{2}\right)^{2}}$. In order to make the equation true, we should satisfy $\quad \frac{2 b \lambda-m^{2}}{4 b \lambda-m^{2}}<1-2 b \lambda \frac{2 b \lambda-m^{2}}{\left(4 b \lambda-m^{2}\right)^{2}}$, and $\frac{2 b \lambda-m^{2}}{4 b \lambda-m^{2}}-\left[1-2 b \lambda \frac{2 b \lambda-m^{2}}{\left(4 b \lambda-m^{2}\right)^{2}}\right]=\frac{-4 b^{2} \lambda^{2}}{\left(4 b \lambda-m^{2}\right)^{2}}<0$. 


\subsection{Numerical Simulation}

In the above part, we build and analyze the models of value co creation in different ways. In this section, we will conduct numerical simulation on these conclusions to facilitate further exploration. The parameters are assumed to be: $a=200, b=3, \lambda=4, c=$ 10. Then, according to proposition (1) and proposition (2), $m=3$ can be assumed. According to proposition (3), we can assume that $\theta<0.625$. According to proposition (4), we can assume $0.27<\alpha<0.59$. The calculation results are as follows:

The results show that the performance of GSC under centralized decision is better than that of GSC with decentralized decision in Steinberg game. Specifically, under centralized decision-making, the green degree of products is higher and the retail price of products is lower, so the demand of users is higher and the profit of the whole supply chain is higher (see Table 2). However, in actual operation, decentralized decisionmaking is often adopted among enterprises, so in order to improve the situation of supply chain, value co creation is needed. When the cost sharing mode value co creation is carried out, the retailers will share part of the green investment cost. When the share ratio is small, the green degree of the product will be improved, the demand will be reduced less, and the manufacturer's profit will be greater than the decentralized decisionmaking, while the retailer will be on the contrary; when the investment ratio continues to rise, the price will rise obviously, and the demand of users will continue to decline The profit is greater than the decentralized decision, but the manufacturer is the opposite. Therefore, there will be conflicts of interest between the two and cannot cooperate to create value together (see Table 3). When the manufacturer and retailer cooperate closely to make overall decision and then distribute the value, the profits of both sides will increase, and the green degree and demand will reach the maximum, which is conducive to the cooperation of the supply chain and the development and production of green products. Both parties can decide the distribution proportion according to different situations (see Table 4)
The "free riding" behavior of retailers will lead to profit conflict between manufacturers and retailers. In order to further improve the operation ability and profit value of the green supply chain, this paper studies the influence of different value co creation methods on the green degree, product demand and the profits of each member and the whole supply chain. The main conclusions are as follows: (1) Compared with the overall decision, the decision quantity of the green supply chain under decentralized decision-making is obviously decreased; (2) There is no appropriate allocation proportion under the cost sharing mode, which makes the mode more meaningful than decentralized decision-making; (3) Under the value distribution mode, as long as the manufacturer and retailer cooperate within a certain range, the price can be achieved Value co creation plays a positive role to achieve the optimal state of the whole chain. The above results show that the value co creation among members of green supply chain is of great significance, which can improve the economic performance of green supply chain, and improve the green degree and sales volume of products. In order to improve the development of green supply chain and achieve the purpose of environmental protection, in addition to enterprises should strengthen cooperation, the government should also strengthen environmental protection publicity, improve consumers' environmental awareness and preference for environment-friendly products.

There are still some limitations in this study. Firstly, the supply chain in this paper is composed of manufacturers and retailers, and there are many members in the actual operation. Therefore, we can add suppliers, consumers and other members to the main body of value co creation. In addition, this paper analyzes the impact of cost sharing and value distribution on co-creation. In the future research, we can consider more ways to provide more guidance for the cooperation of green supply chain.

\section{CONCLUSION}

Table 2. Decisions and Profits of Decentralized and Centralized Models

\begin{tabular}{|l|l|l|l|l|l|l|}
\hline$\theta$ & $g$ & $p$ & $q$ & $\Pi_{M 2}$ & $\Pi_{R 2}$ & $\Pi_{S C}$ \\
\hline Centralized decision & 45.30 & 55.33 & 136.00 & & & 3853.33 \\
\hline Decentralized decision & 13.78 & 62.07 & 55.14 & 1013.29 & 1572.79 & 2343.14 \\
\hline
\end{tabular}


Table 3. Variables and profits under different cost sharing proportion

\begin{tabular}{|c|c|c|c|c|c|}
\hline$\theta$ & $g$ & $p$ & $q$ & $\Pi_{M 2}$ & $\Pi_{R 2}$ \\
\hline 0.1 & 24.11 & 59.56 & 67.50 & 1912.50 & 775.34 \\
\hline 0.2 & 26.73 & 64.56 & 65.54 & 1857.03 & 858.74 \\
\hline 0.3 & 29.53 & 68.26 & 61.25 & 1735.42 & 949.06 \\
\hline 0.4 & 32.14 & 68.86 & 53.68 & 1521.05 & 1049.00 \\
\hline 0.5 & 33.75 & 64.17 & 42.50 & 1204.17 & 1204.17 \\
\hline 0.6 & 32.93 & 53.01 & 28.94 & 819.86 & 1929.08 \\
\hline
\end{tabular}

Table 4. Variables and profits under different value distribution proportion

\begin{tabular}{|c|c|c|}
\hline$\alpha$ & $\Pi_{M 3}$ & $\Pi_{R 3}$ \\
\hline 0.3 & 2697.33 & 1156.00 \\
\hline 0.35 & 2504.66 & 1348.67 \\
\hline 0.4 & 2312.00 & 1541.33 \\
\hline 0.45 & 2119.33 & 1734.00 \\
\hline 0.5 & 1926.67 & 1926.67 \\
\hline 0.55 & 1734.00 & 2119.33 \\
\hline
\end{tabular}

\section{ACKNOWLEDGMENT}

This study is financially supported by the Fundamental Research Funds for the Central Universities (No. 2019JBZ111)

\section{REFERENCES}

[1] Kusi-Sarpong, S.; Gupta, H.; Sarkis, J. A supply chain sustainability innovation framework and evaluation methodology. International Journal of Production Research 2019 Volume 57, pp. 19902008.DOI:https://doi.org/10.1080/00207543.2018. 1518607

[2] Dangelico R M, Pontrandolfo P. From green product definitions and classifications to the Green Option Matrix [J]. Journal of Cleaner Production, 2010, 18(16-17):1608-1628. DOI: https://doi.org/10.1016/j.jclepro.2010.07.007

[3] Suhaiza Zailani, Kannan Govindan, Mohammad Iranmanesh, Mohd Rizaimy Shaharudin,Yia Sia Chong. Green innovation adoption in automotive supply chain: the Malaysian case[J]. Journal of Cleaner Production,2015,108. 1115-1122. DOI: https://doi.org/10.1016/j.jclepro.2015.06.039

[4] Ji, J.; Zhang, Z.; Yang, L. Comparisons of initial carbon allowance allocation rules in an $\mathrm{O} 2 \mathrm{O}$ retail supply chain with the cap-and-trade regulation. Int. J. Prod. Econ. 2017 Volume 187, pp. 68-84. DOI: https://doi.org/10.1016/j.ijpe.2017.02.011
[5] Dai R.; Zhang, J.; Tang, W. Cartelization or Costsharing? Comparison of cooperation modes in a green supply chain. Journal of Cleaner Production 2017 Volume 156, pp. 159-173. DOI: https://doi.org/10.1016/j.jclepro.2017.04.011

[6] C T Zhang, L P Liu. Research on coordination mechanism in three-level green supply chain under non-cooperative game [J]. Applied Mathematical Modelling, 2013, 37(5):3369-3379. DOI: https://doi.org/10.1016/j.apm.2012.08.006

[7] Anni-Kaisa K, Katrina L. The Underlying Potential of Supply Management in Value Creation[J]. Journal of Purchasing\&Supply Management, 2012, 18: 68-75. DOI https://doi.org/10.1016/j.pursup.2012.04.006

[8] Fitzpatrick M, Varey R J , Groenroos C , et al. Relationality in the service logic of value creation[J]. Journal of Services Marketing, 2015, 29(6-7):463-471.

DOI:https://doi.org/10.1108/JSM-01-2015-0038

[9] Mai ShuMin,Su ShuWen,Wang Dong. Patient value co-creation behavior scale based on the DART model. [J]. The American journal of managed care, 2020, 26(9):PP e282-e288. DOI:https://doi.org/ 10.37765/ajmc.2020.88493

[10] Kumar, N., L. K. Scheer, and J.-B. E. Steenkamp. The Effects of Perceive Interdependence on Dealer Attitudes. Journal of Marketing Research, 1995, 32 (3): 348-356. DOI: https://doi.org/10.1177/002224379503200309 
[11] Shi, X.; Li, G.; Dong, C.; Yang, Y. Value CoCreation Behavior in Green Supply Chains: An Empirical Study. Energies 2020, 13, 748-771. DOI: https://doi.org/10.3390/en13153902
[12] Zahra Basiri, Jafar Heydari. A mathematical model for green supply chain coordination with substitutable products [J]. Journal of Cleaner Production, 2017, 145:232-249. DOI: https://doi.org/10.1016/j.jclepro.2017.01.060 